\title{
Assessment of Oil Palm Fresh Fruit Bunches Harvesters Working Postures Using Reba
}

\author{
Nawi, N.S.M. ${ }^{1 . a}$, Deros, B.M. ${ }^{1 . b}$ and Nordin, N. ${ }^{2 . c}$ \\ ${ }^{1}$ Department of Mechanical and Materials Engineering, \\ Faculty of Engineering and Built Environment, \\ Universiti Kebangsaan Malaysia, \\ 43600 UKM, Bangi, Selangor, Malaysia. \\ ${ }^{2}$ Department of Technology Management, \\ School of Technology Management and Logistic \\ Universiti Utara Malaysia \\ 06010 Sintok, Kedah, Malaysia. \\ answanimn@gmail.com, ’hjbaba@eng.ukm.my, 'rani@uum.edu.my
}

Keywords : working postures, oil palm industry, REBA

\begin{abstract}
Ergonomics has plays an important role to improve occupational health and work productivity in most industries in Malaysia including agriculture. However, most of the workers in Malaysia especially in oil palm plantation do not highlight ergonomics awareness as priority for their safety and health. They still using manual tools and consequently exposed to ergonomics risk factors. The objective of this study is to evaluate working postures during harvesting oil palm fresh fruit bunches. The Rapid Entire Body Assessment (REBA) is used to evaluate risks working postures and movements corresponding to the tasks. From the analysis, it is revealed that most of the oil palm workers were affected by musculoskeletal disorders especially on left and right hand side. Immediate action such as conduct ergonomics training for the workers must be taken to solve this ergonomic problem.
\end{abstract}

\section{Introduction}

Manual material handling work usually involves lifting, handling, placing, pushing, pulling, carrying or move heavy loads [1]. When these tasks are performed repeatedly or over prolonged periods, it will expose workers to variety ergonomic risk factor [2]. For example repetitions frequently lead to mental fatigue and physical stress, and it will be worse if the works requires higher focus or take some time to be completed. However most of the works still require workers to perform repetitive tasks associated with heavy work postures and movements [3]. When combining with heavy physical workload, it could lead to work-related muscle disorders (WSMDs) [4;5]. These situations may result in significant number of complaints about discomfort and pain or injuries which are usually caused by inadequate postures during work activities [5].

Agriculture is one of occupational groups that most likely to report daily exposure to variety of musculoskeletal injury hazards as most of the works in this area still use manual tools [6;7]. Several studies have identified that agriculture industry workers are more vulnerable to occupational safety and health problems [8;9]. In oil palm plantation the problems are unavoidable because the workers are still use manual handling when harvesting fresh fruit bunch (FFB). Although there have been several machineries has been adopted, but the plantation are still using manual tools and rely on foreign labor [10;11]. Most of the Malaysian Oil Palm plantation, harvest FFB manually, using a chisel in young palms and a sickle mounted on a bamboo or aluminum pole in taller palms [12]. Each palm can produce between 8 to $15 \mathrm{FFB}$ per year weighing about 15 to $25 \mathrm{~kg}$ each, depending on the planting material and age of the palm [13]. The task of lifting heavy FFB manually could contribute to employee health risk factors [9]. 
Through this research, we will be able to identify working postures associated with discomfort among oil palm workers during harvesting fresh fruit bunch. This study used Rapid Entire Body Assessment (REBA) to observe postural risks in the whole body.

\section{Methodology}

\section{Observation and video recording}

Observational methods are probably the most often used approach to evaluate physical workload in order to identify hazards at work and monitor the ergonomic postures [14;15]. Before conduct posture analysis, authors need to record every work postures. In this study, the author only focuses on harvesting FFB and loading FFB. For each activity, a plantation worker was selected in random to record the posture. The working postures of the subject were recorded using video recorder. This was done to capture the actual of FFB harvesters' activities and postures so that they can be properly assessed in the laboratory. The benefit of using this equipment was that recall of actual work situations was made since it could be time consuming for posture observation.

\section{Rapid Entire Body Assessment (REBA)}

REBA method was applied to analyze risk postures of whole body segments: neck, trunk, legs, arms and wrists. REBA is a method developed by Dr Sue Hignett and Dr Lynn McAtamney to associate risk of musculoskeletal injury with the recorded postures [16]. REBA is a worksheet used to assess entire body movements during performing tasks as shown in Figure 1. REBA score is the sum of two groups of postures. Group A involved trunk, neck and legs postures. Whereas, Group B is of upper arms, lower arms, and wrists body segments.

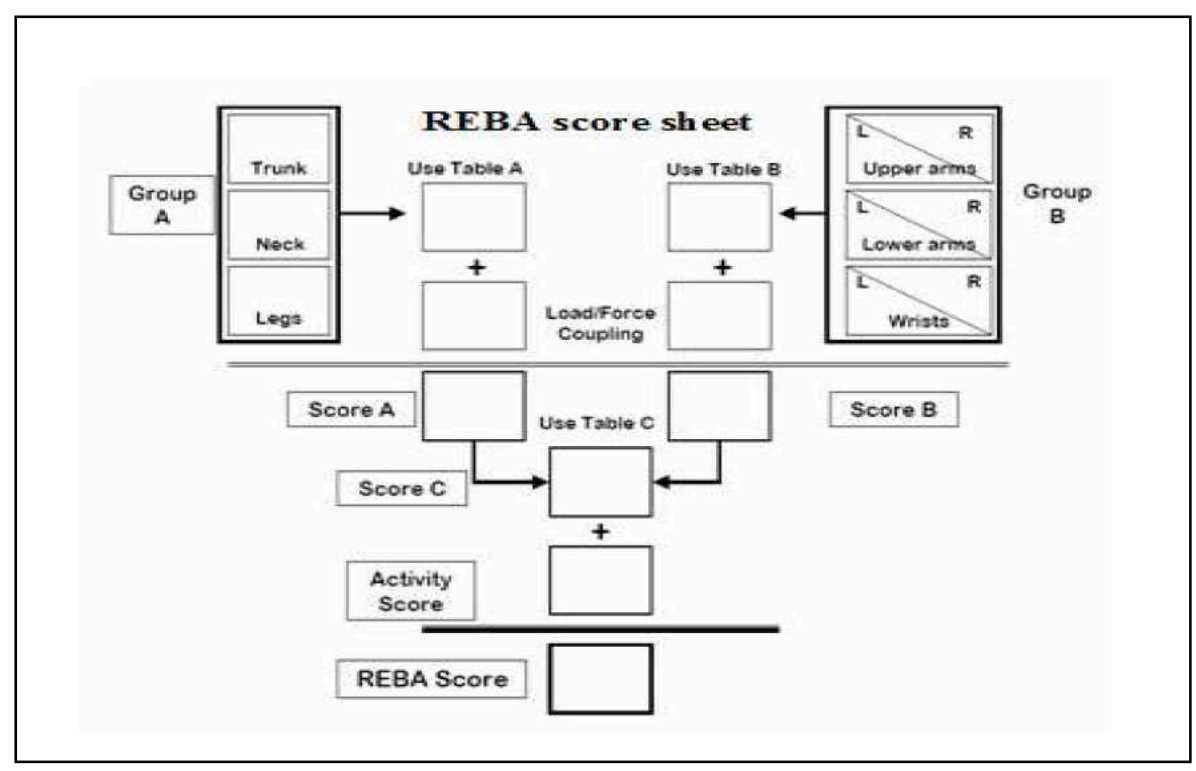

Figure 1 : REBA score sheet

The REBA Score is expressed on a scale of 1 to 15 , as tabulated in Table 1. An analysis of scores represents the work's risks and indicates possible actions to avoid or minimize the risks. 
Table 1: Risk levels of ergonomic injury corresponding to REBA scores and indications

\begin{tabular}{ccc}
\hline REBA score & Risks level & Action needed \\
\hline 1 & Safe & Not necessary \\
2 to 3 & Low & Can be necessary \\
4 to 7 & Medium & It is necessary \\
8 to 10 & High & It is necessary to be done fast \\
11 to 15 & Very high & It is urgent \\
\hline
\end{tabular}

\section{Result and Discussion}

\section{Observation}

After recording the work, there are several typical postures that repeatedly seen were chosen from video recording image. However, an author have categorized into two groups of working postures that have high repetition. Working posture A is when worker harvest FFB manually by using chisel or sickle. Manual cutting of FFB is tough. Harvester must skillful and physically fit in order to have successful cutting operation [17]. When perform this work, worker's back posture is in be precise position as shown in Picture 1 and if the worker continuously performs the job in this position, it will increase the risk of getting injured.
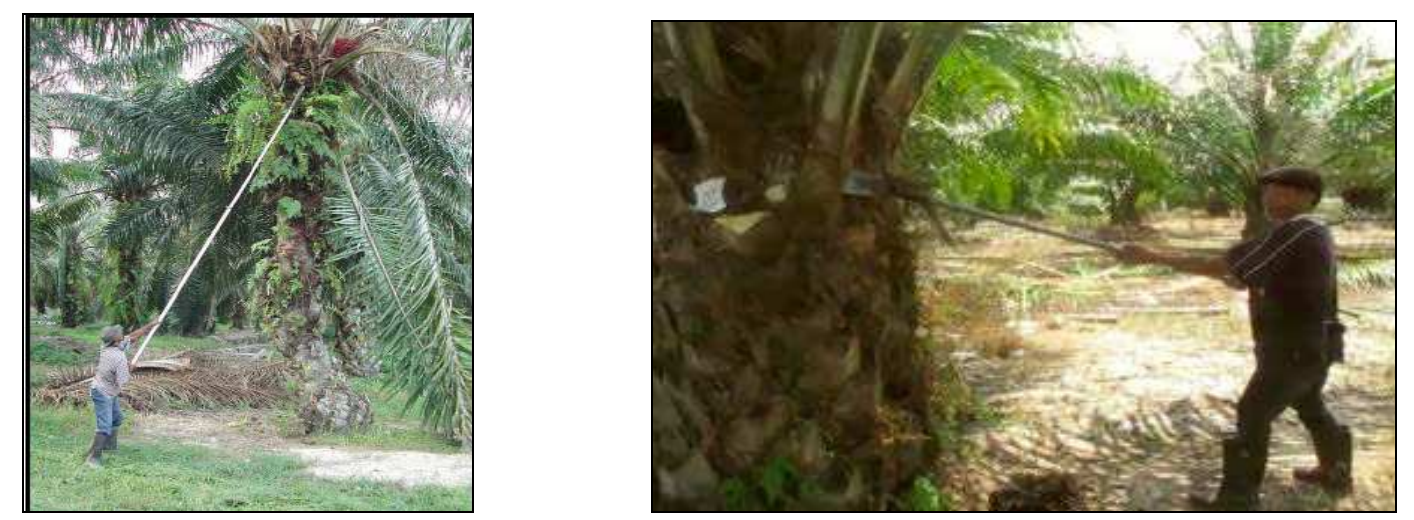

Picture 1: Harvesting of FFB

The working posture B is when farmers collect and lifting FFB from the ground into a wheelbarrow. This posture also requires a lot of effort and make their back posture is bent. The back segment is burden when workers continuously perform the job.
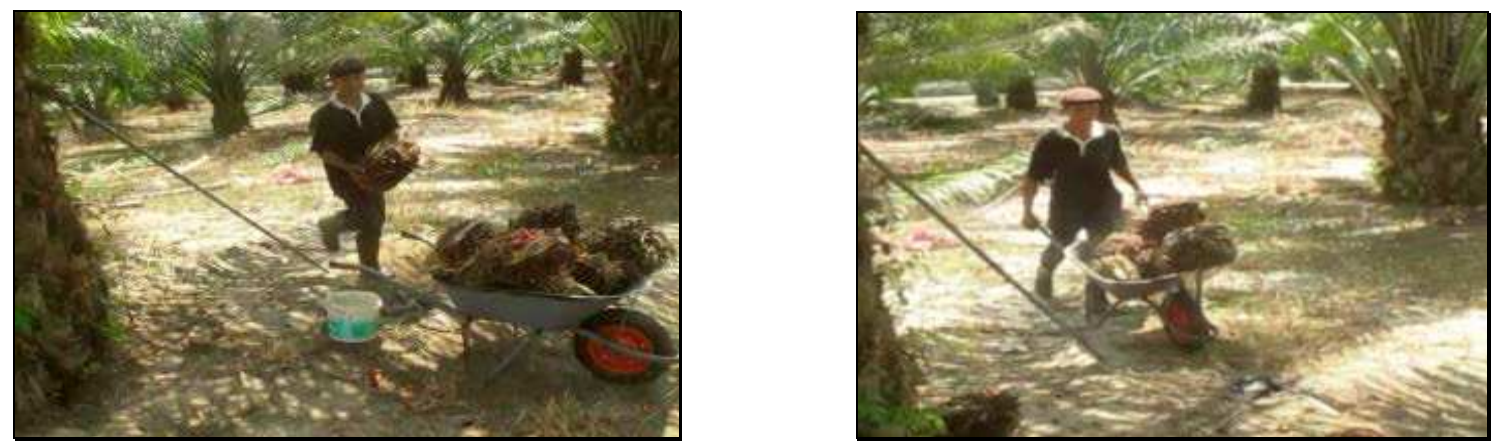

Picture 2: Collecting and loading FFB 


\section{REBA analysis}

The analysis of postures Group A and Group B revealed that most of the postures during harvesting and collecting FFB are highly risky. Table 2 shows the analysis of six selected working postures from high risk value score. From REBA worksheet analysis, the REBA score (sum of group A and group B), found that holding and swinging chisel and sickle are in the 'very high' risk level. These require immediate action to recover safety and health of the workers. A predominance of postures involving right and left hand side was found. It is the result of pressure exerted when holding, pushing and pulling tools while harvesting. These postures have high risk and require intervention and correction to be done as soon as possible in reduce stress and fatigue while using heavy tools.

Table 2 : Analysis of working postures

\begin{tabular}{|c|c|c|c|}
\hline Figure & Activity & REBA score & Risk level \\
\hline & $\begin{array}{l}\text { Holding and swinging chisel strongly } \\
\text { Knees bent } \\
\text { Body leaning forward }\end{array}$ & 13 & Very high \\
\hline & $\begin{array}{l}\text { Holding and swinging chisel strongly } \\
\text { Knees bent } \\
\text { Body straight }\end{array}$ & 8 & High \\
\hline & $\begin{array}{l}\text { Holding and pushing long-armed sickle } \\
\text { Both hand above shoulder level } \\
\text { Body leaning forward }\end{array}$ & 9 & High \\
\hline & $\begin{array}{l}\text { Pulling/pushing long-armed sickle } \\
\text { strongly } \\
\text { Usually more than one time in each } \\
\text { session }\end{array}$ & 13 & Very high \\
\hline & $\begin{array}{l}\text { Lifting bunch from ground } \\
\text { Body bending forward }\end{array}$ & 10 & High \\
\hline & $\begin{array}{l}\text { Carrying bunch from ground into } \\
\text { wheelbarrow }\end{array}$ & 10 & High \\
\hline & Pushing wheelbarrow containing FFB & 8 & High \\
\hline
\end{tabular}

The finding of REBA analysis shows that two critical postures are at a very high level of risk and need immediate action. The postural are when workers holding and swinging chisel strongly and also when holding and pushing long-armed sickle strongly. At this time workers using full force to push and try to drop FFB. The actions usually need to be done repeatedly because oil palm fruit bunches are difficult to be taken. Therefore, the workers need to impose great pressure on the manual tools used, thus facing heavy workload. Form REBA score, the left hand side and right hand side are experiencing high risk and can give injury to the workers if they are not resolved immediately. 


\section{Conclusion}

Improvement of working posture need to be done by improving all aspects that related to physical workload such as by reduce the workload on the back, neck, shoulder/arm, and also hand/wrist. For the repeatability, it is highly related to the user skills, which can be enhanced with appropriate training. Organization or owners of oil palm plantation need to conduct ergonomic training and assessment to identify and control ergonomics risk factors for ensure safety and health of their workers.

\section{References}

[1] Darcor. 2001. The Ergonomics of Manual Material Handling : Pushing and Pulling Tasks. Information on http://www.darcor.com/public/File/pdf/Darcor_Casters_WhitePaper.pdf

[2] Rud, S. (n.d.). 2011. An Ergonomic Analysis of the Current Lifting Techniques in Height Restricted Cargo, 1-64.

[3] Singh, L. P. (2010). Work posture assessment in forging industry : An exploratory study in India. International Journal of Advanced Engineering Technology. (1). 358-366

[4] Ansari, N. A., Shende, P. N., Sheikh, M. J., \& Vaidya, R. D. (2013). Study and Justification of Body Postures of Workers Working In SSI by Using Reba, (3), 505-509.

[5] Varmazyar, S., Amini, M., \& Kiafar, S. (2012). Ergonomic Evaluation of Work Conditions in Qazvin Dentists and its Association with Musculoskeletal Disorders Using REBA Method, 24(3), 182-187.

[6] Chapman, L \& Meyers, J. 2002. Ergonomics and musculoskeletal injuries in agriculture Recognizing and preventing the industry's most widespread health and safety problem. Information on http://agcenter.ucdavis.edu/AgDoc/Erg_Musc_Inj.pdf

[7] Hope, a, Kelleher, C., Holmes, L., \& Hennessy, T. (1999). Health and safety practices among farmers and other workers: a needs assessment. Occupational medicine (Oxford, England), 49(4), 231-5. Information on http://www.ncbi.nlm.nih.gov/pubmed/10474914

[8] C.Solomon.2002.Accidental injuries in agriculture in the UK. Occupational Medicine. 52(8):461-466

[9] Walker-Bone, K., \& Palmer, K. T. (2002). Musculoskeletal disorders in farmers and farm workers. Occupational medicine (Oxford, England), 52(8), 441-50. Information on http://www.ncbi.nlm.nih.gov/pubmed/12488514

[10] Duraj, V.Miles, J.A., Meyers, J.M., Faucett J.A., Janowitz,I.L. (2000). Harvesting aids for reducing ergonomics risk factors in wine grape hand harvesting. Information on http://agergo.ucdavis.edu

[11] Wan, I., Mohd, Z., \& Wan. Z. 1997. Sistem Pengautomatan Jentera Pemungut Tandan Kelapa Sawit. Pertanika J. Sci.\& Technol. 5(2):241-256.

[12] Jelani, A. R., Hitam, A., Jamak, J., Noor, M., Gono, Y., \& Ariffin, O. (2008). Cantas TM - A tool for the efficient harvesting of oil palm fresh fruit bunches. Journal of Oil Palm Research, $20,548-558$. 
[13] Hai, T.C. (2002). The Palm Oil Industry in Malaysia From Seed to Frying Pan. Information on assets.panda.org/downloads/oilpalmchainpartaandb_esri.pdf

[14] Halim, I., \& Omar, A. R. (2011). Posture, muscle activity and oxygen consumption evaluations among metal stamping operators: A pilot study in Malaysian Small and Medium. 72(4).

[15] Takala, E.-P., Pehkonen, I., Forsman, M., Hansson, G.-Å., Mathiassen, S. E., Neumann, W. P., Sjøgaard, G., et al. (2010). Systematic evaluation of observational methods assessing biomechanical exposures at work. Scandinavian Journal of Work, Environment \& Health, $36(1), 3-24$.

[16] Hignett, S., \& McAtamney, L. (2000). Rapid entire body assessment (REBA). Applied ergonomics, 31(2), 201-5. Information on http://www.ncbi.nlm.nih.gov/pubmed/10711982

[17] Jelani, A. R., Shuib, A. R., Hitam, A., Jamak, J., \& Noor, M. M. (2003). Hand-held mechanical cutter. MPOB Infomation Series No. 180, (JUNE), 1-2. 